Doi: $10.15863 / \mathrm{TAS}$

\section{International Scientific Journal Theoretical \& Applied Science}

p-ISSN: 2308-4944 (print) e-ISSN: 2409-0085 (online)

Year: $2014 \quad$ Issue: 12 Volume: 20

Published: $30.12 .2014 \quad$ http://www.T-Science.org

SECTION 19. Management. Marketing. Public administration.
Olga Vladimirovna Panina

Candidate of Economic Science, Docent, a chair of "Public and Municipal Administration"

Department for academic affairs at the

Financial University under the

Government of the Russian Federation ol87691@gmail.com

Marina Konstantinovna Krivtsova the forth-year student, the Chairman of Scientific Student Society of Public and Municipal Administration faculty at the Financial University under the Government of the Russian Federation marinstar@bk.ru

Maria Aleksandrovna Podzorova the forth-year student, the Deputy Chairman of

Scientific Student Society of Public and

Municipal Administration faculty at the Financial University under the Government of the Russian Federation marusia15@inbox.ru

\title{
REMUNERATION OF LABOUR AS A FACTOR OF DETERMINATION OF OVERALL PERFORMANCE OF A PUBLIC SERVANT
}

Abstract: In this work remuneration of labour as a factor of determination of efficiency of public servants' activity is considered. The authors give the detailed characteristic of the main models of creating the system of remuneration of labour of public servants applied in global practice.

Key words: remuneration of labour, government service, efficiency, salary, public servant, Tariff agreement.

Language: Russian

Citation: Panina OV, Krivtsova MK, Podzorova MA (2014) REMUNERATION OF LABOUR AS A FACTOR OF DETERMINATION OF OVERALL PERFORMANCE OF A PUBLIC SERVANT. ISJ Theoretical \& Applied Science 12 (20): 9-12. doi: http://dx.doi.org/10.15863/TAS.2014.12.20.3

\section{ОПЛАТА ТРУДА КАК ФАКТОР ОПРЕДЕЛЕНИЯ ЭФФЕКТИВНОСТИ РАБОТЫ ГОСУДАРСТВЕННОГО СЛУЖАЩЕГО}

Аннотация: В данной работе рассматривается оплата труда в качестве фактора определения эффективности деятельности государственных служащих. Авторами дается детальная характеристика основных моделей построения системы оплаты труда государственных служащих, применяемых в мировой практике.

Ключевые слова: оплата труда, государственная служба, эффективность, оклад, государственный служаший, Тарифный договор.

Финансирование: Статья подготовлена по результатам исследований, выполненных за счет бюджетных средств по Государственному заданию Финуниверситета 2014 года.

Одним из важнейших направлений совершенствования системы государственного управления является внедрение новых принципов кадровой политики в системе государственной гражданской службы, которые должны предусматривать совершенствование системы моральной и материальной мотивации государственных гражданских служащих и стимулировать их антикоррупционное поведение. Безусловным фактором, определяющим эффективность работы государственного гражданского служащего является система оплаты труда.

В международной практике с незначительными отклонениями можно выделить две модели построения системы оплаты труда государственных служащих. Первая характеризуется невысоким уровнем денежного содержания со значительным социальным пакетом, а вторая - относительно высоким денежным содержанием, конкурентным на рынке 
труда и незначительным по объему социальным пакетом [1, с. 236].
Каждая из моделей имеет свои преимущества и недостатки (рис. 1).

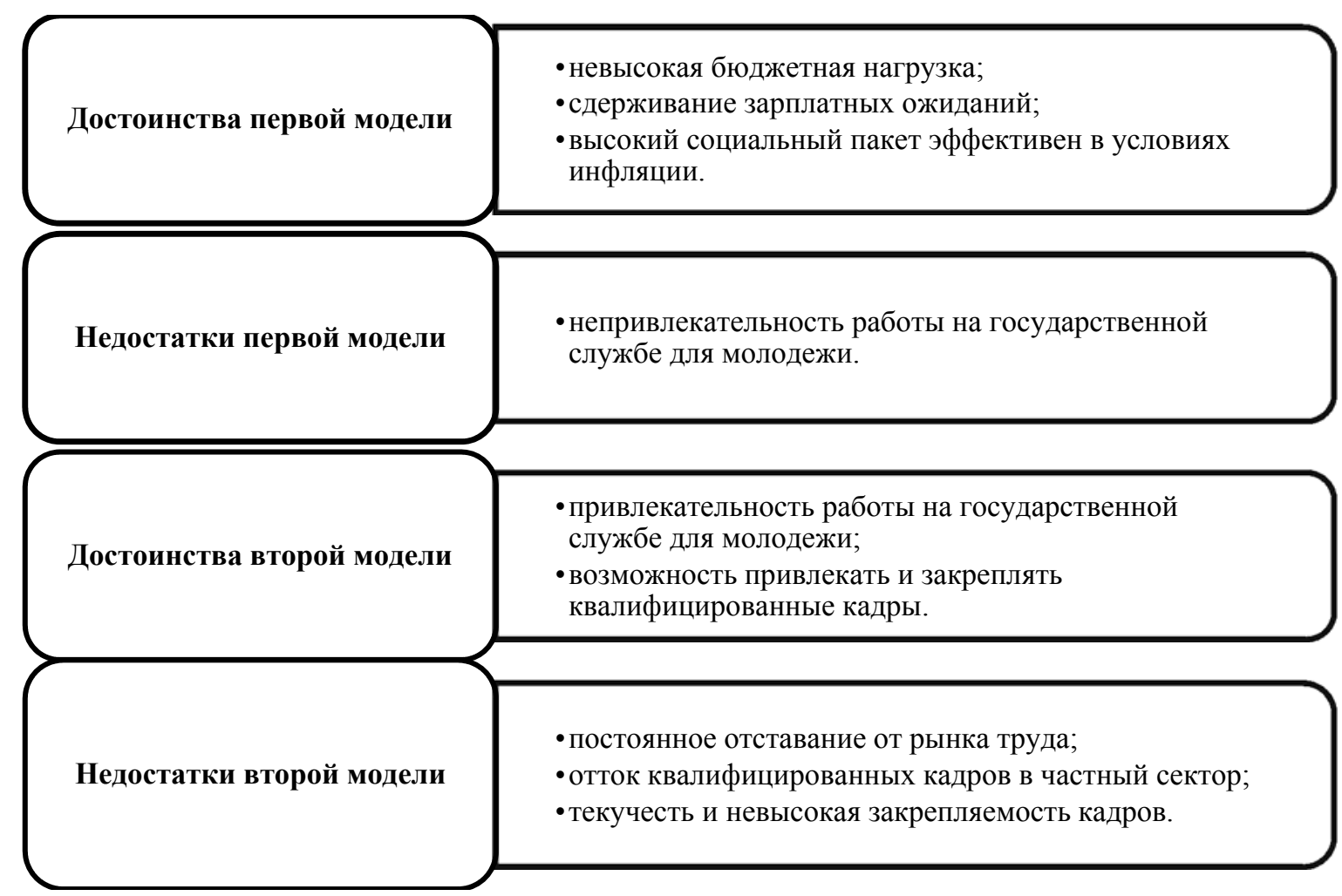

Рисунок 1 - Достоинства и недостатки моделей построения системы оплаты труда государственных служащих

В 2004 году законодательно была введена система оплаты труда в зависимости от результата (pay-for-performance) для высших руководителей, предусмотрена норма обязательного сертифицирования ведомствами своих систем оценки результатов деятельности служащих высшего звена.

В США оплата труда федеральных служащих ведется по Общей тарифной сетке. В ней 15 разрядов, каждый из которых характеризуется соответствующим уровнем сложности работы, ответственности и соответствующими квалификационными требованиями [4, с. 132].

Опыт Германии. Формирование персонала государственной службы имеет вид алгоритма: образование - уровень службы - особенности замещения должности - денежное содержание. В ФРГ существует сводный реестр должностей с указанием сферы деятельности и подгруппы заработной платы. Он утвержден Федеральным законом о денежном содержании (Bundesbesoldungsgesetz).

Человек в системе государственной службы определяется по его знаниям и умениям:
- простая служба - успешное завершение основной школы или получение соответствующего аттестата;

- средняя служба - окончание реальной школы или успешное завершение основной школы, а потом получение профессионального образования или получение соответствующего аттестата;

- повышенная служба - окончание специального высшего заведения или иным образом полученное свидетельство об этом уровне образования;

- высшая служба - законченное, достаточное для всей последующей трудовой жизни высшее образование; для службы в общей системе государственного управления таким образованием считается университетское юридическое, экономическое, финансовое или образование в области социальных наук.

Эти требования закреплены в основных законах и распоряжениях о чиновниках. Вследствие этого в Германии невозможно прийти на высокую должность, не имея соответствующего диплома. Подобное комплектование государственной службы

\section{ISPC European Research,}

Birmingham, United Kingdom 
закрывает дорогу некомпетентным, неподготовленным людям [3, с. 35].

$$
\text { В результате реформирования }
$$

государственной службы, проводившегося с 2004 по 2009 гг., Федеральный закон о денежном содержании был изменен, и количество выплат существенно сократилось. С 1 августа 2011 г. действуют следующие виды выплат:

- основной оклад;

- доплаты на членов семьи только для чиновников групп оплаты А2 - A5;

- доплаты за условия службы;

- выплаты кандидатам при прохождении испытательного срока.

Основными группами оплаты являются группа А - чиновники, в отношении которых действует порядок восходящего продвижения по службе на основе аттестаций и квалификационных экзаменов; В - чиновники, в отношении которых действует установленный оклад и которые не подлежат аттестации и квалификационным экзаменам (это только люди с университетским образованием). Ранее групп оплаты было значительно больше - свои правила действовали для солдат. Сегодня они введены в общую сетку оплаты (А и В). Теперь вся служба, включая военную, подчиняется единым правилам установления денежного содержания. В отдельные группы выведены профессора университетов (группа оплаты W) и судьи (группа оплаты R).

Оплата труда чиновника и бюджетника чрезвычайна прозрачна, все сетки оплаты входят составной, неотъемлемой частью в Закон о денежном содержании чиновников или в Тарифный договор в отношении государственных служащих (бюджетников) $[8$, с. 25].

Ранее система была более сложной, позволявшей использовать широкий набор инструментов для стимулирования чиновников. Сейчас она значительно более плоская, предусматривает линейную карьеру человека: при прохождении аттестации человек переводится со ступени оплаты на ступень; при повышении квалификации - в пределах своего уровня службы из группы оплаты в новую группу оплаты.

Все связано именно с тем, что теперь используются новые стимулирующие надбавки за условия несения службы.

Прежде чем представить эти надбавки, нужно отметить также, что чиновники двух групп - В (высшие должностные лица государственной службы) и W (профессора университетов) - не имеют повышающихся ступеней, здесь все зависит от должности или полученного научного звания и замещаемой должности, и потому шкала - плоская.

Повышающимся является оклад судей низших категорий - здесь есть философия карьерного роста в зависимости от опыта, стажа, в зависимости от качества работы. Однако затем - тоже только установленный оклад, привязанный к должности судьи.

Поощрения могут достигать 15\% от величины годового оклада чиновника. В параграфе говорится, что это не постоянно действующие выплаты: если успехи чиновника снижаются, то не может быть и выплат. Для начинающих чиновников и солдат премии не должны превышать 7\%.

Однако для некоторых категорий чиновников премии могут быть более чем значительными - до $250 \%$ от оклада. Эти выплаты рассчитаны, прежде всего, на тех, кто связан с системами жизнеобеспечения страны, кто сам подвергает собственную жизнь риску [5, c. 448$]$.

В отношении бюджетников в Германии действует Тарифный договор. В соответствии с тарифными договорами с 1 октября 2005 г. начала действовать новая система тарифных разрядов, которая объединила ранее раздельно оплачивавшиеся уровни публичной службы, предусматривается унификация отпусков, выплат на детей и по болезни для всех категорий служащих, ежегодных премиальных выплат.В отличие от ранее действовавшей тарифной сетки ныне принято деление на 15 тарифных разрядов на публичной службе.

Показательно: на коммунальном уровне оклад растет быстрее в первые годы службы. Это сделано для того, чтобы удержать людей, в первую очередь молодежь, особенно тех, кто занят непосредственным оказанием услуг населению, на службе. Затем выплаты выравниваются и становятся такими же, как и для федеральных бюджетников.

В отличие от этого, тарифные договоры для других видов занятости отличаются иными шкалами окладов, например, для тех, кто оказывает социальные услуги эта шкала больше, оклады в начальные годы карьеры растут быстрее, чем у чиновников и федеральных бюджетников.

Принятие нового Тарифного договора преследовало несколько целей. Так, благодаря новой тарифной сетке сокращается количество тарифных разрядов, а сами эти разряды формируются на основе менее чем ста признаков, ранее для этого принималось в расчет около 17 тыс. различных факторов.

Bce 15 разрядов сводятся к единым принципам оплаты труда. Учет опыта работы и 
индивидуальных результатов будет осуществляться на основе шести повышающих оклад ступеней, что делает публичную службу привлекательнее благодаря более лучшей оплате труда на начальных ступенях карьеры [10, с. 261].

Совершенствование системы оплаты труда государственных служащих должно включать следующие элементы:

- формирование четких и обоснованных схем должностных окладов (сеток) (Германия);

- эффективную систему оценки деятельности государственных служащих (США);

- инструментом долгосрочного закрепления кадров должен служить социальный пакет.

Следует отметить, что по сравнению с другими развитыми странами в Японии значительно меньше государственных служащих. Они составляют лишь $8,1 \%$ общего числа работающих. Для сопоставления: в Германии $15,1 \%$, в США - 15,5, во Франции - 22,6\%. Своеобразен и эффективен инструментарий, используемый государственными служащими в процессе совершенствования технической политики и роботизации, принципов социального партнерства, регулирования взаимоотно-шений работодателей и наемных работников, социального страхования и т.д.

Во многом эффективность государственного регулирования экономики объясняется высочайшим профессионализмом, гибкостью и ответственностью государственных служащих, обеспечивающимися прежде всего отработанным механизмом их подготовки, стержнем и фундаментом которой являются пять известных во всем мире японских систем, основанных на традициях и философии нации. Они определяют и пронизывают систему подготовки госслужащих, начиная с отбора будущих чиновников и заканчивая их увольнением $[2$, с. 17].

Система оплаты труда входит в структуру пяти великих японских систем, цементирующих стройную систему подготовки госслужащих.

\section{References:}

1. Butova TV, Dudko MA (2014) Gosudarstvennaya ideologiya, aktual'nost', neobhodimost', vazhnost'. Teoreticheskie i prakticheskie voprosy nauki XXI veka Sbornik statey Mezhdunarodnoy nauchno-prakticheskoy konferencii, pp. 235-239.

2. Butova TV, Dunaeva AI, Udachin NO (2014) Zarubezhnyy opyt reformirovaniya sistemy gosudarstvennoy grazhdanskoy sluzhby. V sbornike: Mehanizmy razvitiya sovremennogo obschestva Sbornik nauchnyh statey po materialam Mezhdunarodnoy zaochnoy nauchnoprakticheskoy konferencii. Laboratoriya prikladnyh iekonomicheskih issledovaniy imeni Keynsa, pp. 16-18.

3. Butova TV, Erhov MV (2008) Biznes kak ob'ekt vozdeystviya gosudarstvennoy vlasti. Federativnye otnosheniya i regional'naya social'no-iekonomicheskaya politika, No. 2, pp. 35.

4. Demidov A (2011) Ocenka rezul'tativnosti deyatel'nosti kak instrument povysheniya kachestva vypolneniya gosudarstvennyh funkciy. Byudzhet - 2011, No. 3, pp. 33.

5. Zerkin DP, Ignatov VG (2012) Osnovy teorii gosudarstvennogo upravleniya. Rostov-naDonu, pp. 448.

6. Kochetkov GB (2010) Nacional'nye modeli upravleniya i ispol'zovanie zarubezhnogo opyta. USA \& Kanada: ekonomika, politika, kul'tura, No.12, pp.73-87.

7. Lazarev V (2010) Problemy obschey teorii prava i gosudarstva. Moscow, Infra-M, pp. 816.

8. Purlik VM (2013) Sravnitel'nyy analiz modeley korporativnogo upravleniya i rossiyskaya praktika. Ekonomicheskiy analiz: teoriya i praktika, No.2, pp.20-27.

9. (2006) Sistemy planirovaniya i ocenki rezul'tativnosti deyatel'nosti gosudarstvennyh grazhdanskih sluzhaschih. Materialy mezhdunarodnoy konferencii Vsemirnogo Banka, Moscow, Izdatel'stvo Vsemirnogo Banka.

10. Hropanyuk VN (2012) Teoriya gosudarstva i prava. Moscow, Omega-L, pp. 384. 